\title{
Numerical and physical simulation of rapid microstructural evolution of gas atomised Ni superalloy powders
}

\author{
Liang Zheng, ${ }^{\mathrm{a}, \mathrm{b}}$, T.L. Lee ${ }^{\mathrm{c}, \mathrm{d}}, \mathrm{Na} \mathrm{Liu}^{\mathrm{a}, \mathrm{b}}$, Zhou Li ${ }^{\mathrm{a}, \mathrm{b}}$, Guoqing Zhang ${ }^{\mathrm{a}}$, J. Mi ${ }^{\mathrm{d}^{*}}$, P.S. Grant ${ }^{\mathrm{e}}$ \\ ${ }^{a}$ Advanced High Temperature Structural Materials Laboratory, Beijing Institute of Aeronautical \\ Materials, P.O. Box 81-1, Beijing 100095, China \\ b 3D Printing Research and Technology Centre, Beijing Institute of Aeronautical Materials, P.O. Box 81- \\ 20, Beijing 100095, China \\ ${ }^{\mathrm{c}}$ ISIS Neutron Source, Rutherford Appleton Laboratory, Harwell Oxford, Didcot, OX11 0QX, UK \\ ${ }^{\mathrm{d}}$ School of Engineering \& Computer Science, University of Hull, Cottingham Road, Hull, HU6 7RX, UK \\ ${ }^{\mathrm{e}}$ Department of Materials, University of Oxford, Parks Road, Oxford, OX1 3PH, UK
}

\begin{abstract}
The rapid microstructural evolution of gas atomised Ni superalloy powder compacts over timescales of a few seconds was studied using a Gleeble 3500 thermomechanical simulator, finite element based numerical model and electron microscopies. The study found that the microstructural changes are governed by the characteristic temperatures of the alloy. At a temperature below the $\gamma^{\prime}$ solvus, the powders maintained the dendritic structures. Above the $\gamma^{\prime}$ solvus temperature but in the solid-state, rapid grain spheroidisation and coarsening occurred, although the fine-scale microstructures were largely retained. Once over the incipient melting temperature of the alloy, microstructural change was rapid, and when the temperature was increased into the solid+liquid state, the powder compact partially melted and then re-solidified with no trace of the original structure, despite the fast timescales. The study reveals the relationship between short, severe thermal excursions and microstructural evolution in powder processed components, and gives guidance on the upper limit of temperature and time for powderbased processes if desirable fine-scale features of powders are to be preserved.
\end{abstract}


Keywords: Ni superalloys; Rapid heating and cooling; Powder consolidation; Electron microscopy; Finite element modelling;

\section{Introduction}

Powders and particulates (or droplets when in the liquid or semi-liquid state) are used in a wide range of manufacturing processes to produce structural and functional components. These processes include sintering (of many different types such as field assisted sintering, spark plasma sintering, hot isostatic pressing, etc.), metal injection moulding, additive manufacturing techniques using lasers, electron beams and other heat sources, thermal spraying to produce coatings, and spray forming to produce bulk preforms. At some point in all of these processes, the powders are subjected to one or more rapid heating and cooling cycles, either in the solid-state (tens of seconds up to hours) to increase diffusion rates that facilitates the consolidation of a powder mass during sintering, or briefly in the liquid state (milliseconds to a few seconds) so the powders mix to some extent, and fuse together. In both cases, the elevated temperature excursion is a key part of the forming stage of the powders into the required component shape. In many metal powder based additive manufacturing processes, especially when a laser is used as the heating source, the metal powders are often subjected to many cycles of heating and cooling at rates of 10 to $10^{4} \mathrm{~K} \mathrm{~s}^{-1}[1,2]$ before the component is fully formed. Most of the understanding of the microstructural changes that take place in those processes has been obtained from studying materials after the processing is complete, which has already experienced many heating/cooling cycles or long time exposure to high temperature [3-9]. Clearly, to fully understand the microstructural evolution of the powders that are subjected to many 
heating/cooling cycles, the very important first step is to quantify and understand what is happening during a single heating/cooling cycle. Unfortunately, there are hardly any systematic studies in open literatures that report the rapid microstructural changes in a single rapid heating/cooling cycle (in the range of seconds and/or tens of seconds) for powders that are subject to a range of characteristic temperatures, such as temperatures around the solvus, solidus temperature, etc. This is the regime that encompasses many rapid materials sintering techniques, some types of additive manufacture and spray forming [10-14]. For example, in the many variants of additive manufacture of alloy powders, the initial transient heating experienced by powders under a laser or electron beam may reach $\sim 10^{4} \mathrm{~K} \mathrm{~s}^{-1}$, followed by many subsequent cycles (of progressively lower severity) as the scanning heat source returns to the same region after each application of another layer of powders, every few seconds depending on the programmed beam path $[10]$.

The dynamics of microstructural change are important because increasingly in these powder-based processes, conditions are manipulated to try and minimise microstructural change or coarsening since the powders often have attractive features (refined grains and secondary phases, metastable phases, low levels of elemental segregation, etc.) that are beneficial if retained into the bulk component.

In this paper, we study the rapid microstructural change of atomised $\mathrm{Ni}$ superalloy powders during a single rapid heating and cooling cycle $\left(\sim 500 \mathrm{~K} \mathrm{~s}^{-1}\right)$ with a short $(\sim 10 \mathrm{~s})$ high temperature holding time. The holding temperatures selected are the key characteristic temperatures for the alloy, i.e. around (above or below) the solvus and solidus temperatures. A Gleeble 3500 thermomechanical simulator was used because it 
can control precisely the heating rates, the targeted temperatures and holding times [15]. A finite element (FE) based model of heat flow in the Gleeble apparatus and the powder compact was also developed to simulate the powder compact internal temperatures, which were otherwise unavailable. The powder microstructures were investigated by various microscopies, including electron microprobe microanalysis (EPMA) and electron backscatter diffraction (EBSD) for elemental segregation and grain morphology changes, respectively. The novelty of this paper is that the relationships between rapid microstructural evolution in tens of seconds at temperatures from below the solvus to above the solidus temperatures are quantified for the first time for the Ni superalloy studied. Furthermore, the upper limit of temperature and time to retain the desirable finescale microstructural features of the powders are also identified, which may provide general guidance for other similar alloys.

\section{Materials and experiments}

Ni superalloy with a composition of Ni-20.2Co-12.9Cr-2.0W-3.9Mo-2.3Ta-3.5Al-3.7Ti$0.03 \mathrm{~B}-0.05 \mathrm{Zr}-0.13 \mathrm{Fe}-1.0 \mathrm{Nb}-0.02 \mathrm{C}$ (wt.\%) was prepared by vacuum induction melting (VIM). The alloy composition was based on the ME3 and low solvus high-refractory (LSHR) alloys - the $3^{\text {rd }}$ generation Ni-based disk superalloys. The alloy was gas atomised using a close-coupled gas atomiser and high purity Ar at a gas pressure of $3 \mathrm{MPa}$. The melt temperature was $1760 \mathrm{~K}$ and the average metal flow rate was $25 \mathrm{~kg} \mathrm{~min}^{-1}$. The atomised powders were sieved and powders from the $63-100 \mu \mathrm{m}$ diameter interval (encompassing the typical mass mean diameter of gas atomised Ni superalloys) were canned under argon atmosphere into cylindrical 304 stainless steel cans (200 mm long, $10 \mathrm{~mm}$ inner diameter and $1 \mathrm{~mm}$ wall thickness). The cans were evacuated at room 
temperature to $1.0 \times 10^{-3} \mathrm{~Pa}$, sealed and hot isostatically pressed (HIP) at $1183 \pm 10 \mathrm{~K}$ and $120 \mathrm{MPa}$ for 2 hours. The HIP was an essential step in producing a coherent powder compact suitable for mounting in the Gleeble apparatus and applying rapid Joule heating, but the HIP temperature and time were deliberately much lower than those used for full consolidation (temperatures needed to achieve a fully dense Ni superalloy power compact during HIP are typically $>1373 \mathrm{~K}$ ). A low temperature minimised microstructural change but nonetheless resulted in a sufficiently coherent Ni superalloy powder compact with close powder contact. Fig. 1a shows a backscattered scanning electron microscopy (SEM) image (taken by using a Zeiss EVO 60 SEM) of part of the cross-section of a typical HIPed powder compact. The average porosity is $19.4 \% \pm 4.4 \%$ determined by the analyses of multiple SEM images using the open source software ImageJ.

Fig. 1b shows the cross-sections of the deeply etched as-atomised powders prior to canning. The powders exhibit fine-scale dendritic structures (the typical secondary dendrite arm spacing is in the range of $1-5 \mu \mathrm{m}$ ) with the inter-dendritic contrast provided by the distinct micro-segregation (see later). Similar cross-sections of the powders after the HIP process in Fig. 1c show that while the relatively low temperature HIP conditions had restricted coarsening, there was nonetheless a morphological change as the dendrites became more rounded.

The HIPed cans were cut into $50 \mathrm{~mm}$ long sections and clamped into the $\mathrm{Cu}$ grips of a Gleeble 3500 thermomechanical simulator. Direct current (DC) was discharged into the specimen through the $\mathrm{Cu}$ grips, generating Joule heating in the powder compact. A rapid increase in temperature to a pre-defined isothermal holding temperature was controlled 
by a K-type thermocouple welded onto the external surface of the can mid-way along its length (Fig. 2a). In order to select the targeted isothermal holding temperatures (Table 1) below and above the alloy $\gamma^{\prime}$ solvus and solidus temperatures, differential scanning calorimetry (DSC) investigations of the powders were carried out in a Netzsch 409C DSC operated at a heating rate of $0.17 \mathrm{~K} \mathrm{~s}^{-1}$ under a circulating Ar atmosphere. From a typical DSC heating cycle shown in Fig. $2 \mathrm{~b}$, the alloy $\gamma^{\prime}$ solvus temperature $\left(T_{\gamma^{\prime}}\right)$, incipient melting temperature $\left(T_{I M}\right)$ and liquidus temperature $\left(T_{L}\right)$ were determined as $1428 \mathrm{~K}$, $1483 \mathrm{~K}$ and $1612 \mathrm{~K}$, respectively. The dissolution temperature of the $\gamma^{\prime}$ precipitates in the DSC can be expected to differ from that during rapid Joule heating. Soucail and Bienvenu [16] studied the variation of $T_{\gamma^{\prime}}$ for heat-treated Ar atomised Astroloy powders when subjected to Joule heating at different heating rates using a Smitweld simulator, showing that $T_{\gamma^{\prime}}$ was dependent on both the heating rate and initial precipitate size. $T_{\gamma^{\prime}}$ for powders with fine $\gamma^{\prime}$ precipitates of an initial size of $0.05 \mu \mathrm{m}$ increased by $\sim 12 \mathrm{~K}$ when the heating rate was increased from $8 \mathrm{~K} \mathrm{~s}^{-1}$ to $300 \mathrm{~K} \mathrm{~s}^{-1}$ using a holding time of only 0.5 s, but changed little with higher heating rates. In the present study, precipitates (including $\gamma^{\prime}$ ) actually started to form in the powders during the HIP process, moving the alloy phase fractions closer to equilibrium $[17,18]$. Therefore, while some difference in $T_{\gamma^{\prime}}$ from DSC measurements and during Joule heating and holding for $10 \mathrm{~s}$ of HIPed powders can be expected, it was likely less than the $12 \mathrm{~K}$ measured for the atomised powders over much shorter timescales.

After reaching the target temperature and holding for $\sim 10 \mathrm{~s}$, the electric current flow was terminated and the specimens were quenched to room temperature via the water-cooled $\mathrm{Cu}$ grip/Gleeble apparatus steel frame. Fig. 3a shows the overall experimental 
arrangement and Fig. $3 \mathrm{~b}$ shows a schematic of a cross-section of the specimen and $\mathrm{Cu}$ grip arrangement.

Although the thermocouple welded at the can surface was essential for controlling the heating and holding cycle, significant differences between the temperature on the can surface and that of the powders inside the can are expected. Therefore, as described later, a numerical model to simulate the transient heat flow for the entire arrangement (including the grip, can and powders) was constructed and then used to calculate the temperatures at the centre of the powder compact.

Table 1: The isothermal holding temperatures and times for the powder compacts.

\begin{tabular}{lll}
\hline Experiment case & $\begin{array}{l}\text { Holding temperature }(\mathrm{K}) \\
\text { Can surface temperature; } \\
\text { (The modelled temperature at the } \\
\text { centre of the powder compact) }\end{array}$ & Holding time (s) \\
\hline$T_{1}$ & $1373(1390)$ & 10 \\
$T_{2}$ & $1423(1441)$ & 10 \\
$T_{3}$ & $1473(1495)$ & 8 \\
$T_{4}$ & $1523(1549)$ & 10 \\
\hline
\end{tabular}

The HIPed and rapidly heated specimens were cut at the mid-length (at the thermocouple position) and subsequently polished and etched using a solution of $\mathrm{HCl}(50$ vol. \%) + $\mathrm{H}_{2} \mathrm{O}_{2}$ (50 vol.\%) for microstructure and elemental mapping analyses using SEM (Zeiss EVO 60), EBSD (JEOL JSM-6480) and EPMA (JEOL JXA-8800). Changes in grain morphology and size were investigated qualitatively in the SEM and quantitatively by EBSD respectively. For the polygonal grains, the grain size $(D)$ of each sample was measured using the mean intercept length method assuming spherical grains [19]. At least $\sim 200$ grains were counted for each sample to obtain sufficient statistics. 


$$
D=K \frac{L}{N}
$$

where $K=1.5$ is a proportionality constant for spherical grains [20], $L$ is the summation of chord length intercepting the grains and $N$ is the number of grain boundary intercepts along the line. Grain sizes were also obtained from the EBSD orientation maps whenever possible, giving excellent agreements with the linear intercept measurements.

\section{Model development}

With reference to Fig. 3b, a $2 \mathrm{D}$ axis-symmetrical model for the heat flow in the grip/can/powder compact arrangement was constructed using the commercial, general purpose FE software Comsol Multiphysics.

The electrical potential field generated by the DC current passing through the specimen is governed by the equations:

$$
\begin{gathered}
\nabla \cdot J=-\frac{\partial \rho_{v}}{\partial t} \\
J=-\sigma \nabla E
\end{gathered}
$$

where $J$ is the electrical current density vector, $\rho_{v}$ is the electric charge density, $t$ is time, $\sigma$ is the electrical conductivity and $E$ is the electrical potential.

The electrical potential distribution between the Gleeble $\mathrm{Cu}$ grips was simulated by prescribing $E=0$ along the surface of the low electrical potential grip and an input current density $\left(J_{i n}\right)$ along the surface of the high electrical potential grip as indicated in Fig. 3 b. $J_{\text {in }}$ was given by: 


$$
-J \cdot n=J_{\text {in }}
$$

where $n$ is the local outward unit normal vector. $J_{\text {in }}$ represents the energy input to the can/powder compact arrangement and thus has a dominant effect on all calculated temperatures, and was unavailable experimentally. Therefore, best-fitting of the calculated surface temperature profiles to the experimental profiles measured from the can surface at mid-length was used initially to estimate $J_{\text {in }}$ at each incremental time step when the model was run to compute the transient heat flow. Although this approach restricted the broader applicability of the model, because the model could only be applied for conditions in which experimental data existed, it had the significant advantage that it eliminated the need for complex and probably inaccurate assumptions. For example, how much is the electrical contact resistance between the Ni superalloy powder compact and the $\mathrm{Cu}$ grip ? This restriction was acceptable in the context of the present work since the key information required was the internal temperature distribution at the mid-length of the can where the maximum temperature was achieved and from where microstructure analyses were performed.

The temperature distribution in the powder compact and the can in 2D axis-symmetrical cylindrical polar coordinates $(z, r)$ was governed by the heat flow equation:

$$
\rho C \frac{\partial T}{\partial t}=\frac{1}{r}\left[\frac{\partial}{\partial z}\left(\lambda \cdot r \frac{\partial T}{\partial z}\right)+\frac{\partial}{\partial r}\left(\lambda \cdot r \frac{\partial T}{\partial r}\right)\right]+\rho L_{f}\left(\frac{\partial f_{S}}{\partial T} \cdot \frac{\partial T}{\partial t}\right)+Q_{V}
$$

where $\rho$ is the density, $C$ is the specific heat capacity, $T$ is the temperature, $z$ is the axial coordinate, $r$ is the radial coordinate, $\lambda$ is the thermal conductivity, $L_{f}$ is the latent heat, $f_{S}$ is the alloy solid fraction and $Q_{V}=J^{2} / \sigma$ is the heat source term due to the current flux. 
To account for any latent heat of melting, an alloy effective heat capacity $\left(C_{\text {eff }}\right)$ was defined as:

$$
C_{e f f}=C-L_{f}\left(\frac{\partial f_{S}}{\partial T}\right)
$$

The volume fractions of the alloy liquid and solid phases during solidification were given by the Scheil function:

$$
\left(1-f_{S}\right)=\left(\frac{T-T_{S}}{T_{L}-T_{S}}\right)^{\left(\frac{1}{1-k}\right)}
$$

where $T_{S}$ and $T_{L}$ are the solidus and liquids temperature of the alloy respectively and $k=$ 0.38 is the partition coefficient obtained by best-fit of Equation (7) to the DSC data between the solidus and liquidus temperatures. The Scheil approach was employed because it had been shown to yield reasonable estimates of the liquid fraction during solidification for a number of Ni-based superalloys [21].

Fig. 4a shows the electrical conductivity of the Ni superalloy and stainless steel can as a function of temperature used in the model taken from [22] and [23], respectively. Because electrical conductivity as a function of temperature was not available for this alloy, the temperature-dependent electrical conductivity data of IN718 (up to $1700 \mathrm{~K}$ ) was used here, which had previously been shown to be similar to that of the Waspaloy [24]. The composition of the Waspaloy is close to the alloy used in this research.

Because the powder compact within the can was porous, the effect of porosity on the transport properties i.e. the thermal and electrical conductivity of the HIPed powders had to be taken into account. Carson et al. [25] studied the effective conductivity of porous materials and showed that the conductivity of materials with internal porosity (e.g. for a 
powder compact) are within the Hashin-Shtrikman (H-S) and effective medium theory (EMT) bounds. Fig. $4 \mathrm{~b}$ shows the effective electrical conductivity $\left(\sigma_{P}\right)$ bounds calculated using the H-S bound in the Maxwell-Eucken model [26]:

$$
\frac{\sigma_{P}}{\sigma}=\frac{2 \sigma+\sigma_{a i r^{-}}-2\left(\sigma-\sigma_{a i r}\right) P}{2 \sigma+\sigma_{\text {air }}+\left(\sigma-\sigma_{\text {air }}\right) P}
$$

and EMT [27]:

$$
(1-P) \frac{\sigma-\sigma_{P}}{\sigma+2 \sigma_{P}}+P \frac{\sigma_{a i r}-\sigma_{P}}{\sigma_{\text {air }}+2 \sigma_{P}}=0
$$

where $P$ is porosity $(=19.4 \%)$ and the electrical conductivity of air $\left(\sigma_{\text {air }}\right)$ was assumed for the porosity. The differences between the H-S and EMT bounds are relatively small when porosity is $<20 \%$ and thus, $\sigma_{P}$ used in the model was averaged from the bounds at $P=$ 0.194 .

The temperature-dependent thermal conductivity and heat capacity of the alloy during solidification were determined by the rule-of-mixtures $[11,28]$ :

$$
\begin{gathered}
\lambda=f_{S} \lambda_{S}+f_{L} \lambda_{L} \\
C=f_{S} C_{S}+f_{L} C_{L} \\
C_{e f f}=C+L_{f}\left(\frac{\partial f_{L}}{\partial T}\right)=f_{S} C_{S}+f_{L} C_{L}+\left[\left(\frac{1}{\left(1-k_{p}\right)\left(T_{L}-T_{S}\right)}\right)\left(\frac{T-T_{S}}{T_{L}-T_{S}}\right)^{\frac{k}{1-k}}\right] L_{f}
\end{gathered}
$$

where subscripts "S" and "L" refer to the solid and liquid, respectively and $f_{L}$ is the alloy liquid fraction.

Since inter-dendritic regions and grain boundaries are the last regions to freeze during the solidification of the atomised powders (relatively enriched in some of the alloying 
elements that preferentially segregate to the liquid, see Fig. 1b), they can be expected to be the first regions to melt (incipient melting) during re-heating and coarsening accelerated in the presence of liquid at grain boundaries [3]. Sintering rates can also be expected to accelerate once liquid is formed, as is well-known from liquid phase sintering studies. Although sintering will give rise to shrinkage of the powder compact, due to the very short high temperature holding times and the added significant complexity, shrinkage effects were ignored in the model.

Fig. 5a shows the calculated Ni superalloy liquid fraction using the best-fit value of $k=$ 0.38 and Eq. 7 with the incipient melting point assumed from the DSC data as the solidus temperature $T_{S}=1483 \mathrm{~K}$ and $T_{L}=1612 \mathrm{~K}$, while Figs. $5 \mathrm{~b}$ and $5 \mathrm{c}$ show the thermal conductivity and the effective heat capacity over the temperature range of 1100-1700 K from Eq.10 and 12 respectively. Other thermo-physical and electrical properties used in the model are shown in Table 2, based on ME3 and LSHR wherever possible, or IN718 where data was unavailable. Actually, the differences in thermo-physical properties of Ni-based alloys with slightly different compositions are relatively small. A convective heat flux boundary was applied at the can surface. The rate of the heat loss due to convection per unit area $\left(\dot{Q}_{c o n}\right)$ is given by:

$$
\dot{Q}_{c o n}=h\left(T-T_{a m b}\right)
$$

where $h=15 \mathrm{~W} \mathrm{~m}^{-2} \mathrm{~K}^{-1}$ is the convective heat transfer coefficient, and $T_{a m b}$ is the ambient temperature. The heat transfer from the $\mathrm{Cu}$ grips to the water cooled steel frame (Fig. 3b) was controlled by a similar expression to Eq. 13, with an interfacial heat transfer coefficient of $h=200 \mathrm{~W} \mathrm{~m} \mathrm{~K}^{-1}$. Heat transfer coefficients were chosen based on previous work and numerical simulations (see below). 
The rate of radiative heat loss per unit area $\left(\dot{Q}_{\text {rad }}\right)$ from the heated can surface was given by:

$$
\dot{Q}_{\text {rad }}=\sigma_{S B} \cdot \varepsilon\left(T^{4}-T_{a m b}^{4}\right)
$$

where $\sigma_{S B}$ is the Stefan-Boltzmann constant, and $\varepsilon=0.65$ is the emissivity for steel [29].

Table 2: Thermophysical and electrical properties of the Ni superalloy [22, 30-33], stainless steel can [23] and the $\mathrm{Cu}$ grips [34].

\begin{tabular}{|c|c|c|c|c|}
\hline $\begin{array}{l}\text { Material } \\
\rho\left(\mathrm{kg} \mathrm{m}^{-3}\right)\end{array}$ & & $\begin{array}{l}\text { Ni superalloy } \\
-1.42 \times 10^{-4} \times T^{2}- \\
0.12 \times T+8336\end{array}$ & $\begin{array}{l}\text { Stainless steel } \\
-5.15 \times 10^{-5} \times T^{2}-0.36 \\
\times T+8020 \\
5.77 \times 10^{-7} \times T^{3}-1.38 \times\end{array}$ & $\begin{array}{l}\mathrm{Cu} \\
8700\end{array}$ \\
\hline \multirow{4}{*}{$\begin{array}{l}C_{\text {eff }}\left(\mathrm{J} \mathrm{kg}^{-}\right. \\
\left.{ }^{1} \mathrm{~K}^{-1}\right)\end{array}$} & $293 \mathrm{~K}<T<T_{S}$ & $0.1496 \times T+392.04$ & $\begin{array}{l}10^{-3} \times T^{2}+1.21 \times T+ \\
206\end{array}$ & 385 \\
\hline & $T=T_{S}$ & 652.7 & - & - \\
\hline & $T_{S}<T<T_{L}$ & $C+L_{f}\left(\frac{\partial f_{L}}{\partial T}\right)$ & - & - \\
\hline & $T \geq T_{L}$ & 720 & - & - \\
\hline \multirow{2}{*}{$\begin{array}{l}\lambda\left(\mathrm{W} \mathrm{m}^{-1}\right. \\
\left.\mathrm{K}^{-1}\right)\end{array}$} & $293 \mathrm{~K}<T<T_{S}$ & $0.0153 \times T+4.91$ & $\begin{array}{l}-2.13 \times 10^{-6} \times T^{2}+ \\
0.0176 \times T+9.84\end{array}$ & 400 \\
\hline & $\begin{array}{l}T_{S} \\
T_{S}<T<T_{L} \\
T>T_{L}\end{array}$ & $\begin{array}{l}29.4 \\
f_{S} \lambda_{S}+f_{L} \lambda_{L} \\
23.4\end{array}$ & - & - \\
\hline$L_{f}\left(\mathrm{~kJ} \mathrm{~kg}^{-1}\right)$ & & 256 & - & - \\
\hline \multirow[t]{2}{*}{$\sigma\left(\mathrm{S} \mathrm{m}^{-1}\right)$} & $293 \mathrm{~K}<T \leq T_{S}$ & $\begin{array}{l}0.11 \times T^{2}-239.12 \times T \\
+0.87 \times 10^{6}\end{array}$ & $\begin{array}{l}-4.22 \times 10^{-4} \times T^{3}+1.63 \\
\times T^{2}-2260 \times T+1.93 \times \\
10^{6}\end{array}$ & $\begin{array}{l}-9.91 \times 10^{-2} \times T^{3}+ \\
289 \times T^{2}-2.96 \times \\
10^{5} \times T+1.21 \times 10^{8}\end{array}$ \\
\hline & $T_{S}<T<T_{L}$ & $\begin{array}{l}7.06 \times 10^{-2} \times T^{2}-283 \\
\times T+1.01 \times 10^{6}\end{array}$ & 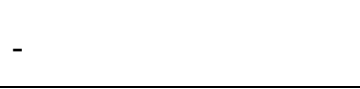 & 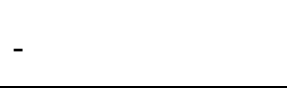 \\
\hline
\end{tabular}

The powder-can interface was assumed to be perfectly conductive, i.e. the thermal contact resistance at the interface was assumed to be zero. This is justified because the microstructural examination of the powder-can interface after HIPing showed that the Ni alloy powders diffusion-bonded closely to the stainless steel can inner surface (Fig. 1a). A similar assumption was also made for the $\mathrm{Cu}$ grip-can interface. It is noteworthy that the uncertainty in the thermal contact resistance at the $\mathrm{Cu}$ grip-can interface does not 
affect the validity of the simulated temperature distribution in the mid-length region of the specimen where the highest temperature was achieved and where microstructure analyses were performed.

\section{Results and discussion}

\subsection{Specimen thermal history and validation}

Fig. 6a shows the measured and simulated specimen surface temperatures at the thermocouple measurement point as a function of time when heated to different isothermal holding temperatures. As described earlier, with all other parameters fixed in the heat flow simulation, the electric current fluxes were tuned in the simulation to achieve the best match between the simulated and the measured temperature profile for each case. For example, Fig. $6 \mathrm{~b}$ shows the simulated temperature distribution across the powder compact cross-section for the $T_{2}$ case immediately before cooling. The hottest region was at the mid-point of the length of the specimen, with temperature gradients along both the axial and radial directions.

The simulated axial temperature gradient existed because of the current density distribution in the axial (Fig. 7a) direction during heating. The current density was the highest (up to $\sim 33.1 \mathrm{MA} \mathrm{m}^{-2}$ ) at the mid-point of the specimen in the axial direction, resulting in the highest temperature in this region (Fig. 7b) under all conditions. Radial temperature gradients also existed due to heat loss from the specimen surface (Fig. 7c). The difference between the simulated maximum temperature in the central region of the specimen $\left(T_{\text {centre }}\right)$ and the temperature at the can surface $\left(T_{\text {surface }}\right)$ increased proportionally with the increase of the isothermal heat treatment temperature, as shown in Fig. 7 d, i.e. 
the temperature difference became larger as the target temperature increased. For the case of $T_{1}$, the Ni superalloy powder compact in the central region reached a maximum temperature of $\sim 1390 \mathrm{~K}$. While for $T_{2}$, the powders were heated to $\sim 1441 \mathrm{~K}$ (13 K above $\left.T_{\gamma^{\prime}}\right)$. For $T_{3}$, the powders were heated to $\sim 1495 \mathrm{~K}\left(12 \mathrm{~K}\right.$ above $\left.T_{I M}\right)$ and a maximum temperature of $\sim 1549 \mathrm{~K}\left(f_{L}=0.51\right)$ was reached for $T_{4}$. The temperature gradients from the specimen mid-point were $2.7-4.3 \mathrm{~K} \mathrm{~mm}^{-1}$ and $52-59 \mathrm{~K} \mathrm{~mm}^{-1}$ in the radial and axial directions respectively, as shown in Figs. 7e and f. The radial temperature gradient was calculated from the specimen mid-point to the can surface, while the axial temperature gradient was determined from the specimen mid-point to the temperature plateau region at $\sim 5 \mathrm{~mm}$ or $\sim 45 \mathrm{~mm}$ along the central axis.

\subsection{Microstructural change}

Figs. 8a and $\mathrm{b}$ show the microstructures of the powders after HIP and heat treatment at $T_{1}=1390 \mathrm{~K}\left(T_{1}\right.$ to $T_{4}$ are now the simulated temperatures at the centre of the powder compact rather than surface temperatures measured from the thermocouple, as clearly shown in Table 1). For the case $T_{1}$, there was no significant change in the as-HIPed microstructure, with the remnants of the dendritic microstructure of the gas atomised powders retained after the low temperature HIP. For the case $T_{2}$, the powders in the central region reached $1441 \mathrm{~K}$ (just above the $T_{\gamma^{\prime}}$ ) in Fig. 8c, the relatively fine-scale primary $\gamma$-Ni dendrites transformed to polygonal, more equiaxed grains; and grain growth occurred even over a period of just $10 \mathrm{~s}$. Residual dendritic structures co-existed with the newly formed equiaxed grains. For the case $T_{3}\left(12 \mathrm{~K}\right.$ above $\left.T_{I M}\right)$ in Fig. $8 \mathrm{~d}$, the transition from the as-solidified fine-scale dendritic structures to equiaxed grains was complete in $8 \mathrm{~s}$ or less; and grain growth and coalescence were widespread. This is a very important 
finding, and it defines the lower temperature limit and the higher temperature limit that can be used in powder consolidation processes to maintain the beneficial microstructures of the original powders in a relative short period of high temperature exposure, i.e. the processing temperature has to be operated between the $\gamma^{\prime}$ solvus temperature and the incipient melting temperature with a tolerance of about 12 degree centigrade. This is very useful for powder sintering or powder HIPing processes where normally the processing temperatures used are well below the alloy incipient melting temperature, and hence very long holding time (many hours). This study demonstrates that the desired microstructures can be realised with much shorter processing time by applying a carefully designed higher temperature between the $\gamma^{\prime}$ solvus temperature and near or even slightly above the incipient melting temperature. For the highest heating case $\left(T_{4}=1549 \mathrm{~K}\right)$ in Fig. $8 \mathrm{e}$ where melting was expected, any residual prior particle boundaries (PPBs) associated with the original powders had melted and a significantly more consolidated compact was formed, with a near-fully equiaxed, coarsened microstructure and newly formed porosity from the liquid. Dendritic structures now had a primary spacing in the 10 to $20 \mu \mathrm{m}$ range.

The grain size as a function of the holding temperature is shown in Fig. 8f, where the mean linear intercept estimates gave good agreement with the EBSD measurement. There was only slight coarsening $(\sim 2 \mu \mathrm{m})$ below the alloy $\gamma^{\prime}$ solvus temperature, although absolute measurements of grain size by either technique in this regime were questionable since the fine-scale dendrite morphologies were far from spheroidal. Significant grain coarsening occurred when the powders were heated to just above the alloy $\gamma^{\prime}$ solvus temperature, with a near doubling in grain size. The relatively slight grain coarsening below the $\gamma^{\prime}$ solvus and much faster growth above the solvus suggested that even if 
precipitation was relatively restricted during the HIP partial consolidation step, it was nonetheless sufficient to provide some grain morphology/size stabilisation (at least over short timescales). However, once dissolved, significant morphological changes and grain coarsening rapidly took place. As shown in Fig 8f, grain sizes increased more dramatically around the incipient melting temperature.

Backscatter electron images in Figs. 9a to c for as-HIPed, $T_{2}$ and $T_{4}$ heat-treated powders, and the corresponding EBSD orientation maps in Figs. 9d to f, underline the rapid transition from the as-solidified fine-scale columnar dendritic structure to the coarser polygonal, equiaxed grains. The spheroidisation of the dendritic structure cannot be deconvoluted from coarsening, both of which occurred in a number of seconds once temperatures beyond the alloy $\gamma^{\prime}$ solvus and incipient melting point were achieved.

The corresponding EPMA maps for Ti, W, Ta and $\mathrm{Nb}$ in Figs. $9 \mathrm{~g}$ to $\mathrm{i}$ for as-HIPed, $T_{2}$ and $T_{4}$ heat treated powders, taken from the red boxed regions, are shown in Figs. 9a to c. In the as-HIPed condition, the $\mathrm{Ti}, \mathrm{W}, \mathrm{Ta}$ and $\mathrm{Nb}$ maps showed micro-segregation into the inter-dendritic or dendritic regions, over length-scales of a few $\mu \mathrm{m}$ : $\mathrm{Ti}$, $\mathrm{Ta}$ and $\mathrm{Nb}$ segregated into the inter-dendritic channels (binary partition coefficient with $\mathrm{Ni}<1$ ), W segregated to the primary $\gamma$-Ni dendritic core region (binary partition coefficient with $\mathrm{Ni}>$ 1), and consistent with other work [35]. The zig-zag grains boundaries in Fig. 9a support the earlier inference of some limited precipitation in the low temperature HIP process, and the subsequent Joule heating cycle, was sufficient to provide a certain degree of grain morphology stabilisation by the Zener pinning effects. The element maps show that while some of the inter-dendritic solidification micro-segregation was likely reduced by HIPing 
(acting as a homogenisation heat treatment), diffusion rates of these elements were too slow to eradicate the solidification micro-segregation entirely. In contrast, following a rapid heat treatment to a higher temperature at $T_{2}$, significant homogenisation of the microstructure occurred, due to faster solid-state diffusion in the localised regions and any incipient grain boundary melting in the regions of particularly strong microsegregation that provided a homogenising effect as liquid solute-rich regions mixed with solvent Ni-rich regions, although a "trace" of the starting elemental segregation was retained within the new, largely equiaxed microstructures. It is reasonable to assume that at $T_{2}$ it is primarily the rapid dissolution of the $\gamma^{\prime}$ (and possibly very fine MC-carbides not resolved in these techniques) and the loss of its grain stabilising effects that leads to the rapid grain spheroidisation and growth.

At $T_{4}$, the extent of re-melting was significantly greater so that any benefits of the finescale dendritic structures, the short diffusion distances, and a microstructural scale constrained to the powder diameter were entirely lost - the powder compact re-solidified as a single bulky material. Although some solid remained at $T_{4}$, and again spheroidised and coarsened, the re-solidification of the integral, relatively dense powder mass was comparatively slow so that a relatively coarse cellular/dendritic structure and significant inter-cellular micro-segregation resulted. As shown in the EMPA maps, microsegregation now led to the formation of distinct, comparatively coarse $\mathrm{Ti}$, Ta and $\mathrm{Nb}$-rich particles, which were most likely MC carbides $[35,36]$ in the inter-dendritic regions. The dendritic arm spacing of the newly formed dendrites was nearly an order of magnitude larger than of the original powders because of the relatively slow cooling rate of the now integrated, coherent and comparatively large powder compact. Overall the benefits of the 
rapidly solidified powder microstructure were largely lost at $T_{4}$ (51\% liquid fraction). Again the finding here is very relevant to the layer-by-layer processing techniques or, in general, the powder-based additive manufacturing techniques involving the remelting of metal powders. If the remelting temperature applied is approaching or above $50 \%$ of liquid fraction when a layer is added on top of the other even in a time scale of $\sim 10 \mathrm{~s}$, generally, the beneficial fine microstructures of the original powders will be completely lost and microsegregation occurs. Subsequently appropriate thermomechanical processing methods are needed to regain the desired microstructures, if needed.

In summary, even over short timescales of a few seconds, the presence of a minority fraction of liquid in the microstructure of powders has a profound effect on microstructure: this can be advantageous if homogenisation and faster consolidation are desired, but should be avoided if retaining the fine-scale microsegregation, grains and precipitates associated with rapidly solidified powders is important. In the case of Ni superalloys, the temperature interval between the solvus and solidus offers a compromise, allowing homogenisation of inter-dendritic micro-segregation, without excessive grain or carbide coarsening.

\section{Conclusions}

Rapid microstructural changes of gas atomised Ni superalloy powders were studied using a Gleeble 3500 thermomechanical simulator and finite element numerical model. Microstructural characterisation using SEM, EPMA and EBSD methods showed that temperature played a critical role in controlling the extent of microstructural evolution in the powders. At a temperature below the $\gamma^{\prime}$ solvus temperature, the powders maintained 
the original dendritic structure. Above the $\gamma^{\prime}$ solvus temperature, grain spheroidisation and coarsening occurred rapidly. Once the temperature was above the incipient melting temperature of the segregated inter-dendritic regions, dramatic grain coarsening occurred. Consequently, the original dendritic microstructures with a characteristic length-scale restricted to the powder diameter disappeared. At a temperature of $1549 \mathrm{~K}$ ( $\sim 0.51$ liquid fraction), the powders were agglomerated with fast consolidation, and re-solidified as a coherent larger volume at a slower cooling rate and with a coarser cellular/dendritic structures and significant, coarser scale micro-segregation. The findings provide a more quantitative understanding of the relationship between thermal history and microstructure in powder processed components subject to short, severe thermal excursions, and give guidance on the upper limits of temperature and time that can be used in powder basedmaterial processes if desirable microstructural features of the powders are to be preserved into the bulk.

\section{Acknowledgements}

The authors would like to acknowledge the research fund provided by the UK Royal Academy of Engineering (The Research Exchange with China and India Award for the project between University of Hull and Beijing Institute of Aeronautical Materials), the International Science \& Technology Cooperation Program of China (Grant No. 2012DFA50240), National Natural Science Foundation of China (Grant No. 51304177),

National Science and Technology Support Program (Grant No. 2015BAE03B01), National Key Research and Development Program of China (Grant No. 2016YFB0701404) and National High Technology Research and Development Program of China (Grant No.2012AA03A514). T.L. Lee gratefully acknowledges the PhD 
studentship awarded by the University of Hull. J. Mi also would like to thank for the financial support by the Royal Society Industry Fellowship.

\section{References}

[1] B. Zheng, Y. Zhou, J. Smugeresky, J. Schoenung, E. Lavernia, Thermal behavior and microstructural evolution during laser deposition with laser-engineered net shaping: Part I. Numerical calculations, Metallurgical and Materials Transactions A 39(9) (2008) 22282236.

[2] X. Liang, J.C. Earthman, E.J. Lavernia, On the mechanism of grain formation during spray atomization and deposition, Acta Metallurgica et Materialia 40(11) (1992) 30033016.

[3] E.D. Manson-Whitton, I.C. Stone, J.R. Jones, P.S. Grant, B. Cantor, Isothermal grain coarsening of spray formed alloys in the semi-solid state, Acta Materialia 50(10) (2002) 2517-2535.

[4] E. Tzimas, A. Zavaliangos, Evolution of near-equiaxed microstructure in the semisolid state, Materials Science and Engineering: A 289(1-2) (2000) 228-240.

[5] N.E. Glover, C.L. Davis, Thermal cycle simulation of a Ni-base superalloy, Scripta Materialia 34(5) (1996) 675-684.

[6] L.N. Carter, C. Martin, P.J. Withers, M.M. Attallah, The influence of the laser scan strategy on grain structure and cracking behaviour in SLM powder-bed fabricated nickel superalloy, Journal of Alloys and Compounds 615 (2014) 338-347.

[7] T. Wang, Y. Zhu, S. Zhang, H. Tang, H. Wang, Grain morphology evolution behavior of titanium alloy components during laser melting deposition additive manufacturing, Journal of Alloys and Compounds 632 (2015) 505-513.

[8] Y. Tian, D. McAllister, H. Colijn, M. Mills, D. Farson, M. Nordin, S. Babu, Rationalization of microstructure heterogeneity in Inconel 718 builds made by the direct laser additive manufacturing process, Metallurgical and Materials Transactions A 45(10) (2014) 4470-4483.

[9] Y.M. Arısoy, L.E. Criales, T. Özel, B. Lane, S. Moylan, A. Donmez, Influence of scan strategy and process parameters on microstructure and its optimization in additively manufactured nickel alloy 625 via laser powder bed fusion, The International Journal of Advanced Manufacturing Technology (2016) 1-25.

[10] A. Simchi, Direct laser sintering of metal powders: Mechanism, kinetics and microstructural features, Materials Science and Engineering: A 428(1) (2006) 148-158.

[11] J. Mi, P.S. Grant, Modelling the shape and thermal dynamics of Ni superalloy rings during spray forming. Part 2: Thermal modelling - Heat flow and solidification, Acta Materialia 56(7) (2008) 1597-1608.

[12] T.L. Lee, J. Mi, S.L. Zhao, J.F. Fan, S.Y. Zhang, S. Kabra, P.S. Grant, Characterization of the residual stresses in spray-formed steels using neutron diffraction, Scripta Materialia 100(0) (2015) 82-85.

[13] A. Mostafaei, E.L. Stevens, E.T. Hughes, S.D. Biery, C. Hilla, M. Chmielus, Powder bed binder jet printed alloy 625: Densification, microstructure and mechanical properties, Materials \& Design 108 (2016) 126-135. 
[14] Y.S. Lee, W. Zhang, Modeling of heat transfer, fluid flow and solidification microstructure of nickel-base superalloy fabricated by laser powder bed fusion, Additive Manufacturing 12, Part B (2016) 178-188.

[15] W. Zhang, A.J. Bodey, T. Sui, W. Kockelmann, C. Rau, A.M. Korsunsky, J. Mi, Multi-scale Characterisation of the 3D Microstructure of a Thermally-Shocked Bulk Metallic Glass Matrix Composite, Scientific reports 6 (2016).

[16] M. Soucail, Y. Bienvenu, Dissolution of the $\gamma^{\prime}$ phase in a nickel base superalloy at equilibrium and under rapid heating, Materials Science and Engineering: A 220(1-2) (1996) 215-222.

[17] A.M. Ritter, M.F. Henry, Precipitation in an as-atomized nickel-based superalloy powder, Journal of Materials Science 17(1) (1982) 73-80.

[18] X. Pierron, A. Banik, G. Maurer, J. Lemsky, D. Furrer, S. Jain, Sub-solidus HIP process for $\mathrm{P} / \mathrm{M}$ superalloy conventional billet conversion, in: T.M. Pollock et. al. (Eds.), Proceedings of the Superalloys 2000, TMS, Champion, PA, 2000, pp. 425-433.

[19] J.-H. Han, D.-Y. Kim, Analysis of the proportionality constant correlating the mean intercept length to the average grain size, Acta Metallurgica et Materialia 43(8) (1995) 3185-3188.

[20] R.L. Fullman, Measurement of particle sizes in opaque bodies, Journal of Metals 5 (1953) 447-452.

[21] B. A. Boutwell, R. G. Thompson, N. Saunders, S. K. Mannan, J.J. deBarbadillo, Phase Formation Modeling of an Alloy 706 Casting Using Computational Thermodynamics, in: E.A. Loria (Ed.), Proceedings of the Superalloys 718,625,706 and Various Derivatives, TMS, Warrendale, PA, 1997, pp. 99-106.

[22] D. Basak, R. Overfelt, D. Wang, Measurement of specific heat capacity and electrical resistivity of industrial alloys using pulse heating techniques, International journal of thermophysics 24(6) (2003) 1721-1733.

[23] C.Y. Ho, T. Chu, Electrical resistivity and thermal conductivity of nine selected AISI stainless steels, Report No. CINDAS-45, Thermophysical and Electronic Properties Information Analysis Center, Lafayette, IN, 1977.

[24] Available from: http://www.goodfellow.com/.

[25] J.K. Carson, S.J. Lovatt, D.J. Tanner, A.C. Cleland, Thermal conductivity bounds for isotropic, porous materials, International Journal of Heat and Mass Transfer 48(11) (2005) 2150-2158.

[26] Z. Hashin, S. Shtrikman, A Variational Approach to the Theory of the Effective Magnetic Permeability of Multiphase Materials, Journal of Applied Physics 33(10) (1962) 3125-3131.

[27] R. Landauer, The Electrical Resistance of Binary Metallic Mixtures, Journal of Applied Physics 23(7) (1952) 779-784.

[28] C. Swaminathan, V. Voller, A general enthalpy method for modeling solidification processes, Metallurgical Transactions B 23(5) (1992) 651-664.

[29] W.F. Gale, T.C. Totemeier, Smithells metals reference book, 8th ed., ButterworthHeinemann, Oxford, UK, 2004.

[30] C. Jeanfils, J. Chen, H. Klein, Modeling of Macrosegregation in Electroslag Remelting of Superalloys, in: J.K Tien et. al. (Eds.), Proceedings of the Superalloys 1980, ASM, Champion, PA, 1980, p. 119.

[31] S.L. Semiatin, F. Zhang, R. Larsen, L.A. Chapman, D.U. Furrer, Precipitation in powder-metallurgy, nickel-base superalloys: review of modeling approach and 
formulation of engineering methods to determine input data, Integrating Materials and Manufacturing Innovation 5(1) (2016) 3.

[32] T.P. Gabb, J. Gayda, J. Telesman, P.T. Kantzos, Thermal and mechanical property characterization of the advanced disk alloy LSHR, Technical Report No. NASA/TM2005-213645, Washington, DC: NASA, 2005.

[33] P. Quested, K. Mills, R. Brooks, A. Day, R. Taylor, H. Szelagowski, Physical property measurement for simulation modelling of heat and fluid flow during solidification, in: A. Mitchell, P. Auburtin (Eds.), Proceedings of the 1997 international symposium on liquid metal processing and casting, AVS, Sante Fe, 1997, pp. 1-17.

[34] V. Rudnev, D. Loveless, R.L. Cook, M. Black, Handbook of Induction Heating, Marcel Dekker, New York, USA, 2003.

[35] L. Zheng, G. Zhang, T.L. Lee, M.J. Gorley, Y. Wang, C. Xiao, Z. Li, The effects of $\mathrm{Ta}$ on the stress rupture properties and microstructural stability of a novel Ni-base superalloy for land-based high temperature applications, Materials \& Design 61(0) (2014) 61-69.

[36] G. Bi, C.-N. Sun, H.-C. Chen, F.L. Ng, C.C.K. Ma, Microstructure and tensile properties of superalloy IN100 fabricated by micro-laser aided additive manufacturing, Materials \& Design 60 (2014) 401-408. 

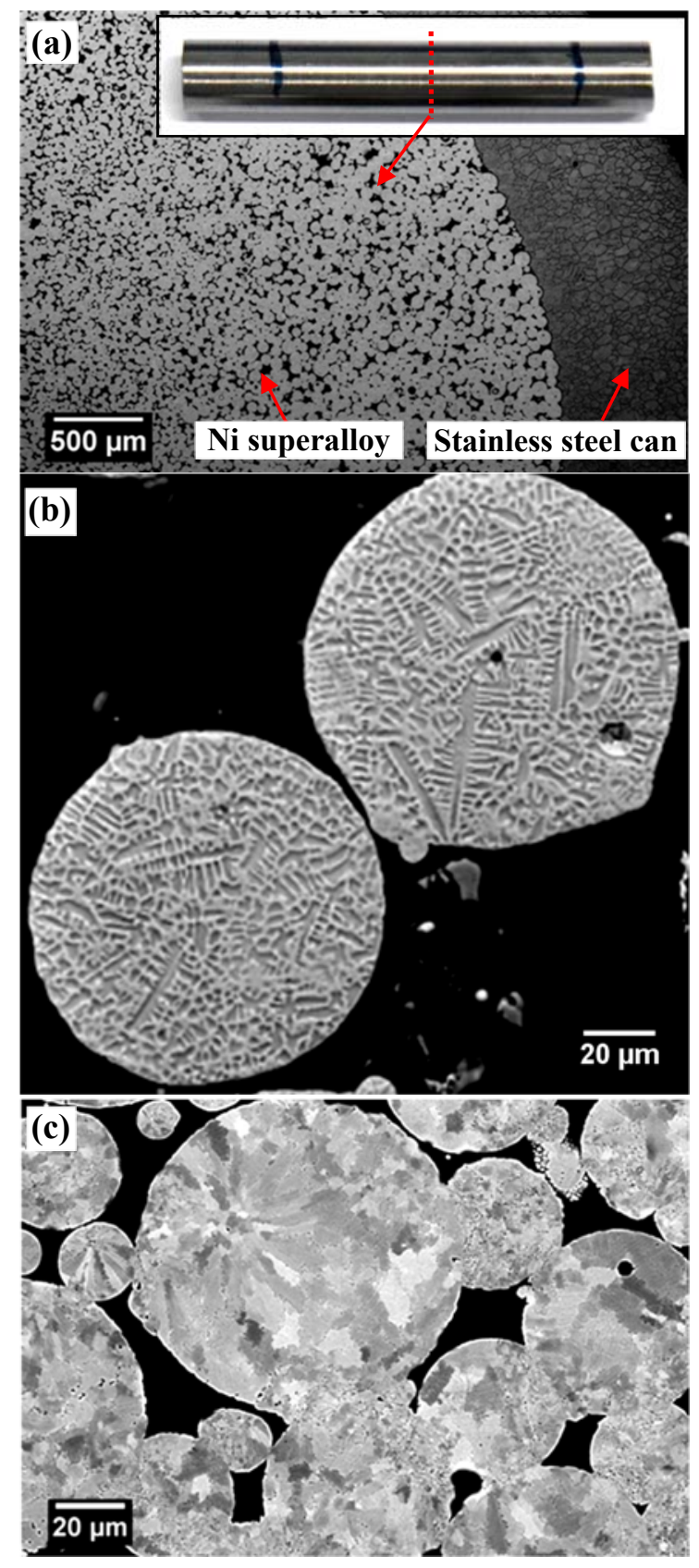

Fig. 1. (a) A backscattered electron image of the HIPed Ni superalloy powders in the stainless steel can (figure inset). (b) The microstructure of the deeply etched as-atomised powders, and (c) the microstructure of the powders after HIP at $1183 \mathrm{~K}$ and $120 \mathrm{MPa}$ for 2 hours. 

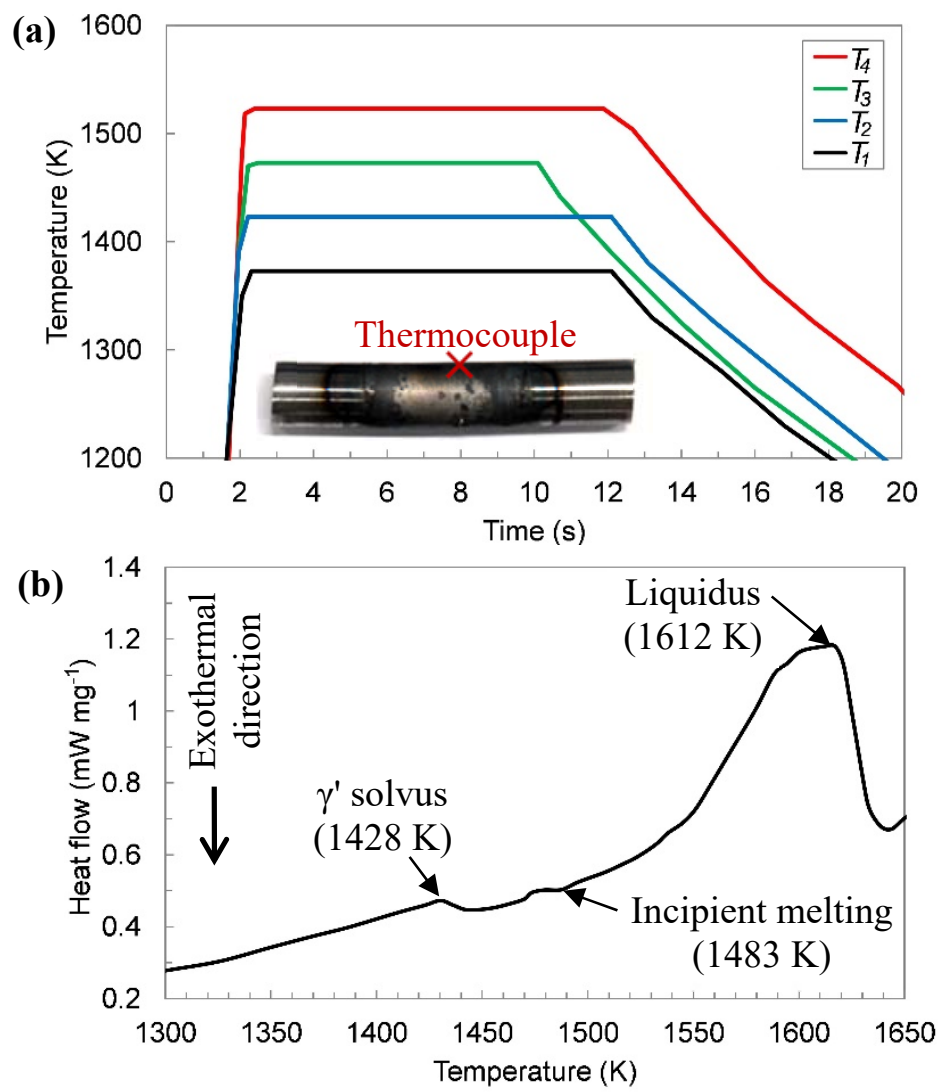

Fig. 2. (a) The measured temperature profiles at the stainless steel can surface. The temperature measurement position is marked by the red cross in the inset figure. (b) The measured $\gamma^{\prime}$ solvus, incipient melting and liquidus temperatures of the Ni superalloy powders determined by using DSC. 

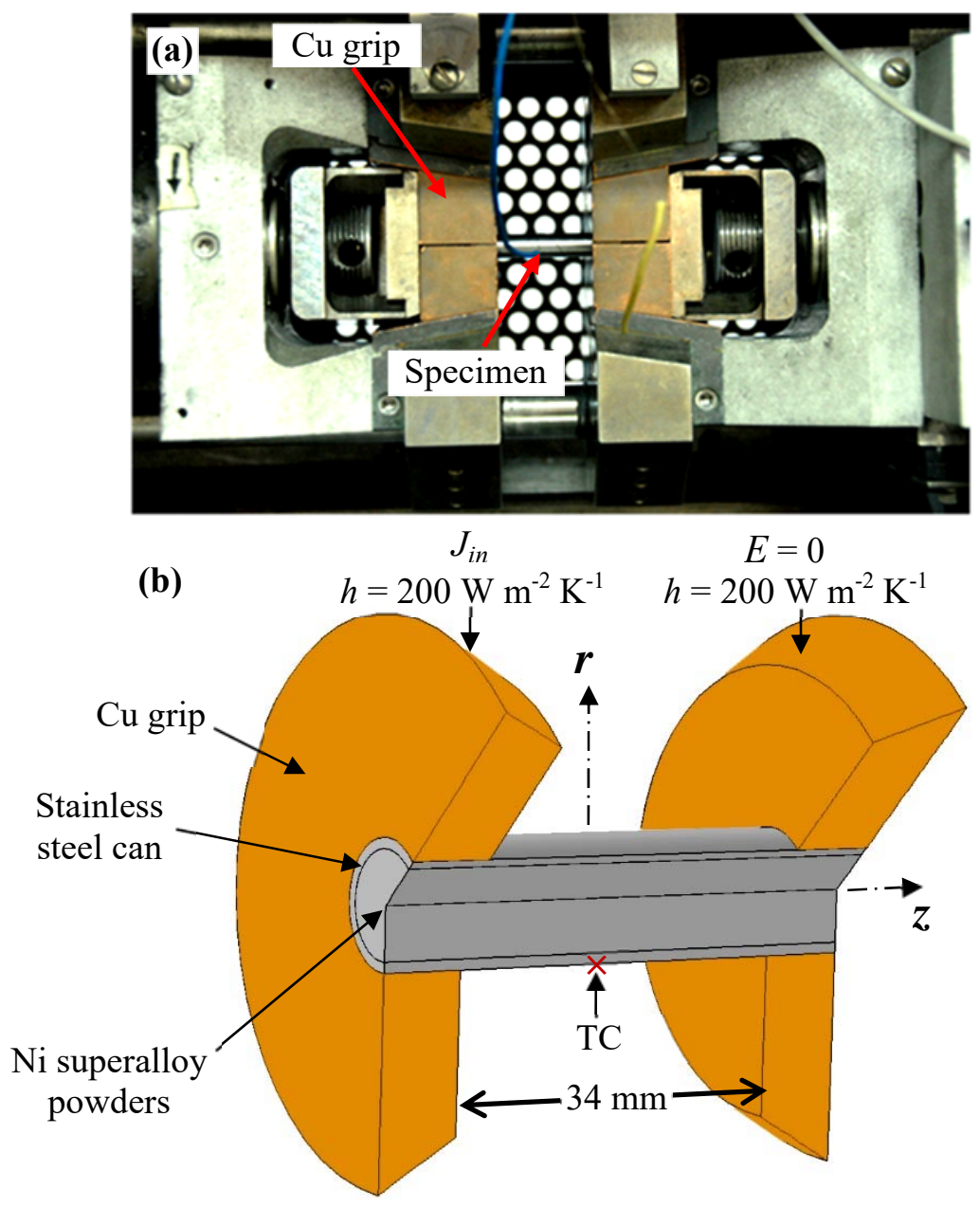

Fig. 3. (a) A general overview of the Gleeble rapid heating/cooling experimental arrangement. (b) A schematic of the cross-section of the experimental arrangement, showing the location of the thermocouple (TC), the boundary conditions, and assumptions used in the finite element heat flow model. 

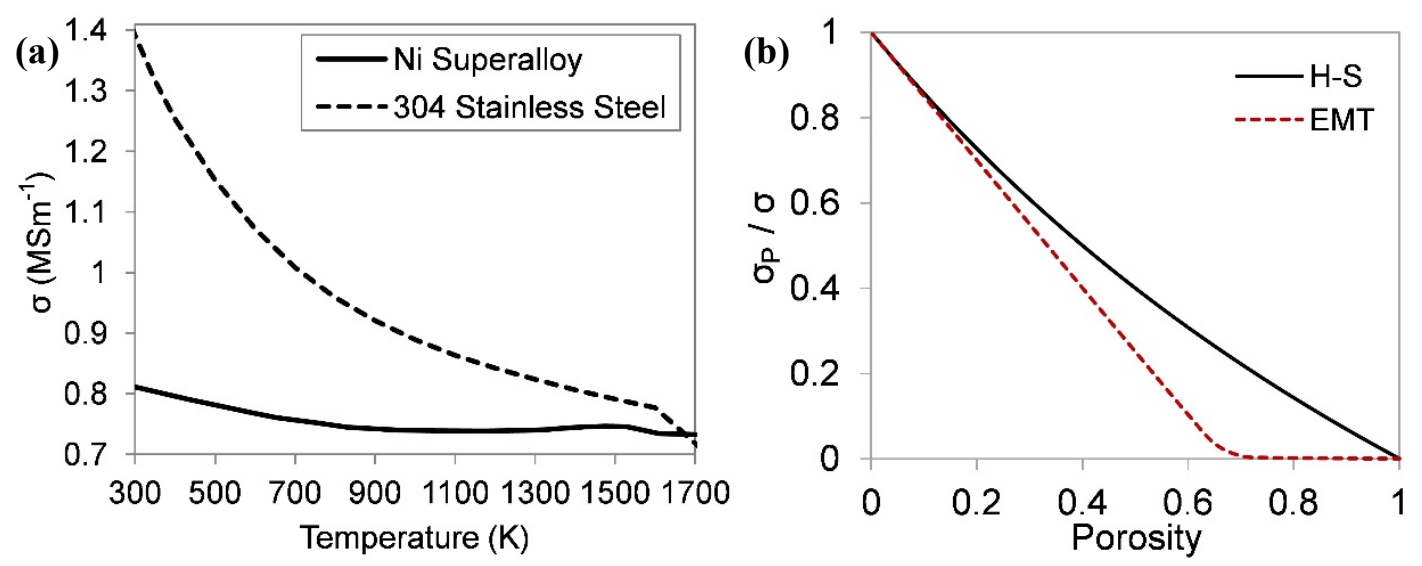

Fig. 4. (a) The electrical conductivity of the Ni superalloy and stainless steel as a function of temperature taken from [22] and [23], respectively. (b) The Hashin-Shtrikman (H-S) and effective medium theory (EMT) bounds of the effective electrical conductivity as a function of porosity. 
(a)

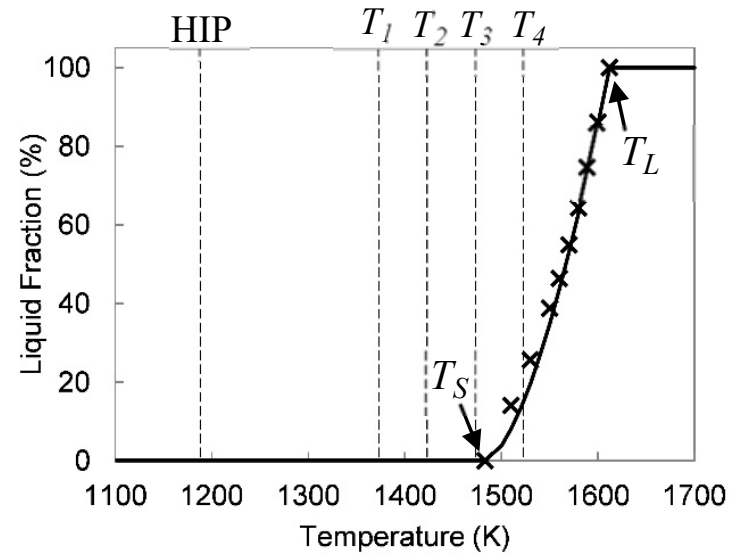

(b)
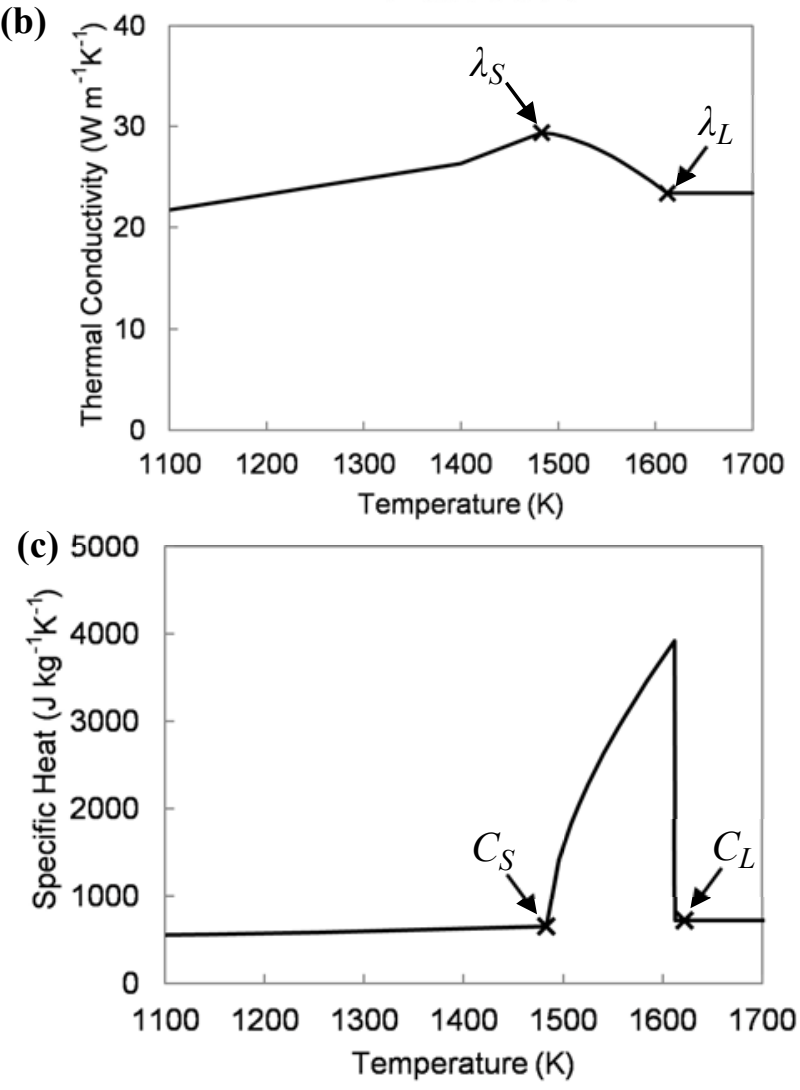

Fig. 5. The calculated Ni superalloy (a) liquid fraction, (b) thermal conductivity and (c) effective heat capacity as a function of temperature. The measured data are marked by $\times$. 


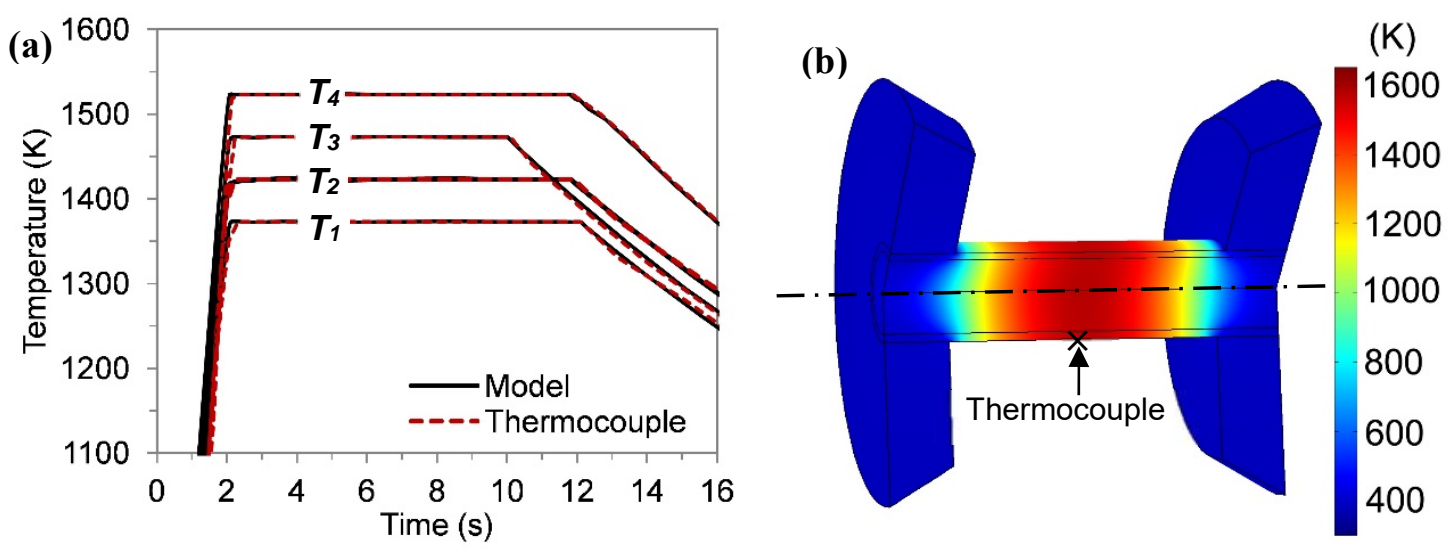

Fig. 6. (a) The measured and simulated specimen surface temperatures at the thermocouple measurement point for the four cases $\left(T_{1}, T_{2}, T_{3}\right.$ and $\left.T_{4}\right)$. (b) The simulated specimen cross-sectional temperature distribution for the $T_{2}$ case immediately before cooling. 

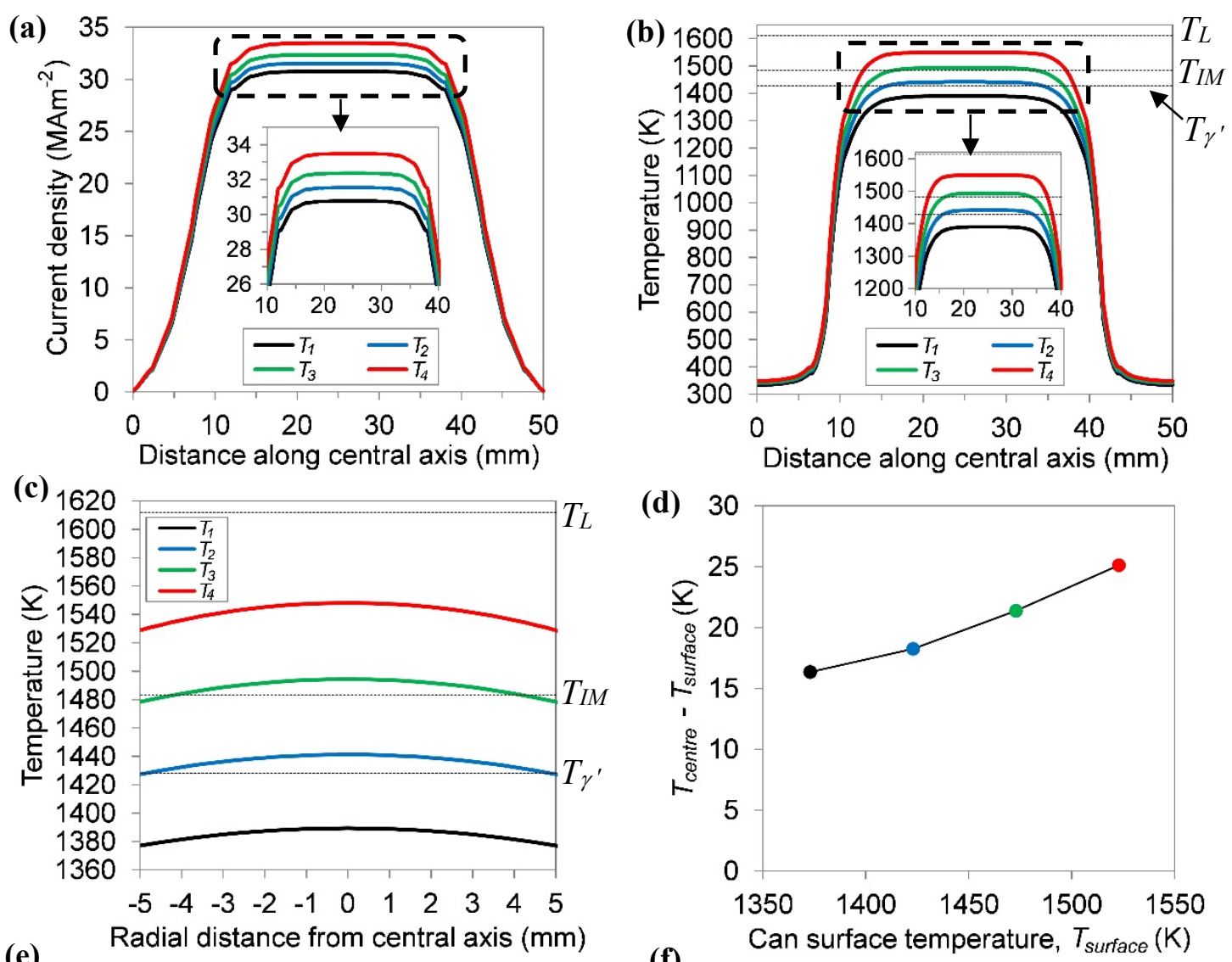

(e)
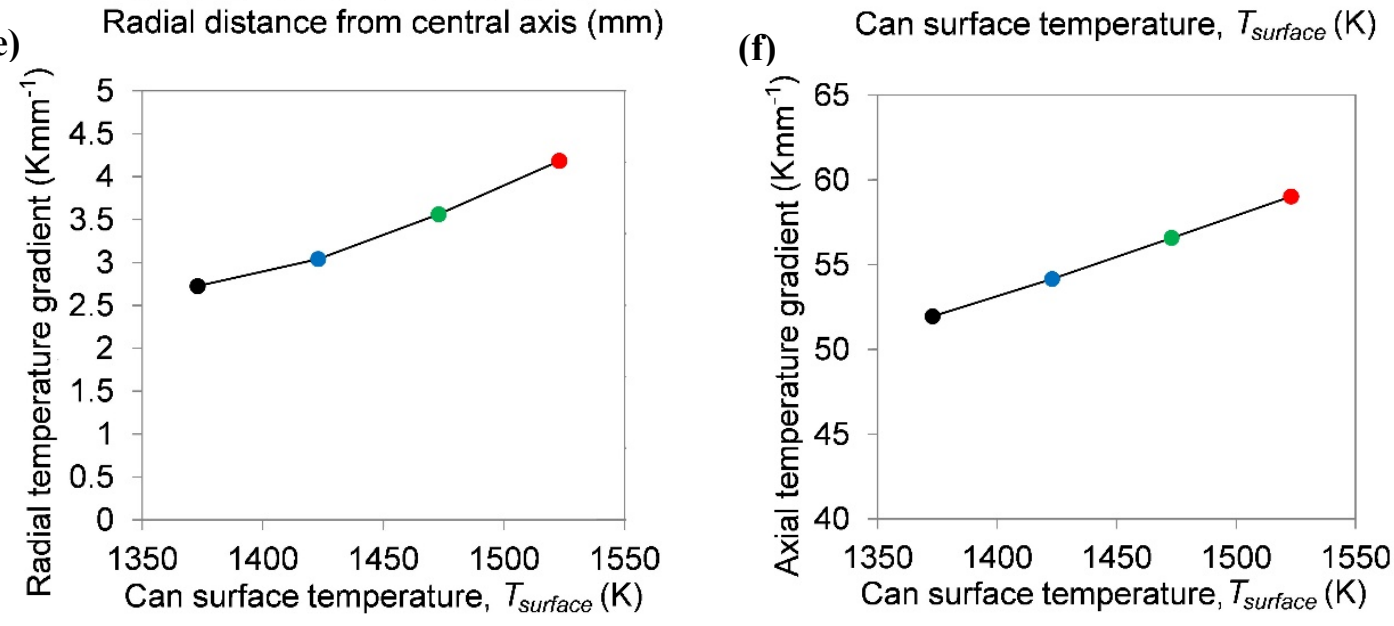

Fig. 7. (a) The specimen axial current density distribution, (b) axial temperature distribution, (c) radial temperature distribution, (d) difference between the maximum temperature in the central region of the specimen $\left(T_{c e n t r e}\right)$ and the temperature at the can surface $\left(T_{\text {surface }}\right)$ for the four cases, (e) radial temperature gradient as a function of the target heating temperature and (f) axial temperature gradient as a function of the target heating temperature. 


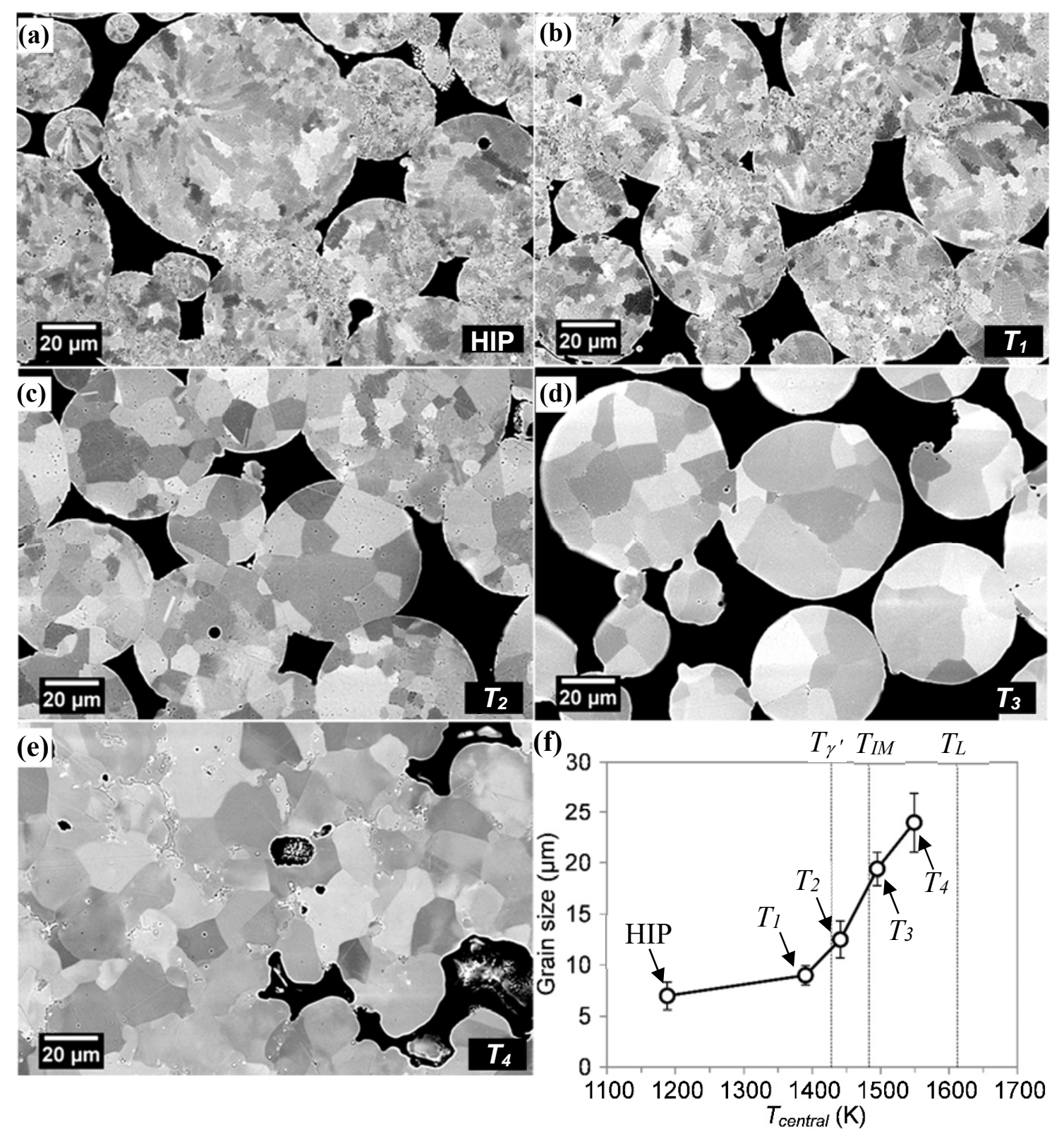

Fig. 8. The microstructures of the Ni superalloy powders in the central region of the specimen after (a) HIP (dendritic structure), thermally shocked to the temperatures of (b) $T_{1}$ (dendritic structure), (c) $T_{2}$ (dendritic and equiaxed structure), (d) $T_{3}$ (equiaxed structure), and (e) $T_{4}$ (equiaxed structure with newly formed porosity). (f) The grain size measured with respect to the simulated temperature in the central region of the specimen for the four cases. A uniform specimen temperature distribution during HIP was assumed. 


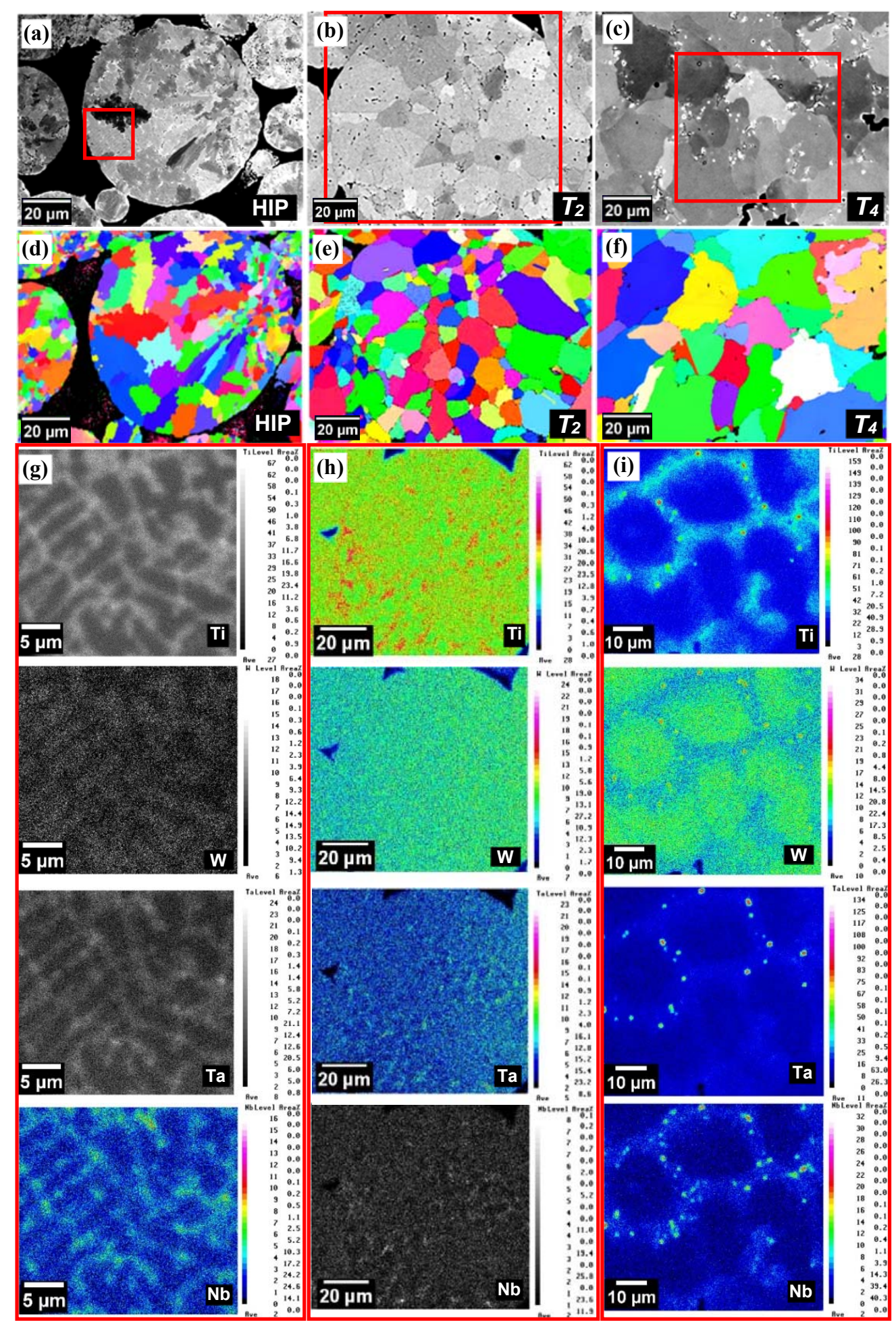

Fig. 9. The SEM micrographs of the (a) HIPed and (b), (c) rapidly heated Ni superalloy powders to $T_{2}$ and $T_{4}$ respectively, (d-f) the corresponding EBSD orientation maps, and (g-i) the corresponding EPMA maps for $\mathrm{Ti}, \mathrm{W}$, Ta and $\mathrm{Nb}$ from the red bounded box regions marked in the SEM images. 